\title{
Recombinant dHER2 Vaccine
}

National Cancer Institute

\section{Source}

National Cancer Institute. Recombinant dHER2 Vaccine. NCI Thesaurus. Code C49177.

A cancer vaccine consisting of a truncated recombinant HER2 peptide (dHER2) with potential antineoplastic activity. Upon administration, recombinant dHER2 vaccine may stimulate the host immune response to mount a cytotoxic T-lymphocyte response against tumor cells that overexpress the HER2 protein, resulting in tumor cell lysis. The HER2 protein is a tumor-associated antigen (TAA) that is overexpressed in a variety of cancers. dHER2 includes the extracellular domain (ECD) and a part of the intracellular domain (ICD) of the HER2 protein. 